\title{
Functional Recovery After Wharton's Jelly-Derived Mesenchymal Stem Cell Administration in a Patient with Traumatic Brain Injury: A Pilot Study
}

\author{
Serdar KABATAS ${ }^{1,2,3}$, Erdinc CIVELEK ${ }^{1,2}$, Gulseli Berivan SEZEN ${ }^{1}$, Necati KAPLAN ${ }^{4}$, Eyup Can SAVRUNLU1, \\ Ercan CETIN ${ }^{1}$, Furkan DIREN ${ }^{1}$, Erdal KARAOZ ${ }^{5,6,7}$ \\ 'University of Health Sciences, Gaziosmanpaşa Training and Research Hospital, Department of Neurosurgery, Istanbul, Turkey \\ ${ }^{2}$ Marmara University, Institute of Health Sciences, Department of Pediatric Allergy-Immunology, Istanbul, Turkey \\ ${ }^{3}$ University of Health Sciences, Center for Stem Cell and Gene Therapy Research and Practice, Istanbul, Turkey \\ ${ }^{4}$ Istanbul Rumeli University, Corlu Reyap Hospital, Department of Neurosurgery, Istanbul, Turkey \\ ${ }^{5}$ Istinye University, Faculty of Medicine, Department of Histology and Embryology, Istanbul, Turkey \\ ${ }^{6}$ Liv Hospital, Center for Regenerative Medicine and Stem Cell Research \& Manufacturing (LivMedCell), Istanbul, Turkey \\ ${ }^{7}$ Istinye University, Center for Stem Cell and Tissue Engineering Research and Practice, Istanbul, Turkey
}

Corresponding author: Eyup Can SAVRUNLU esavrunlu@gmail.com

To watch the surgical videoclip, please visit http://turkishneurosurgery.org.tr/uploads/jtn-31732-video-1.mp4 http://turkishneurosurgery.org.tr/uploads/jtn-31732-video-2.mp4; http://turkishneurosurgery.org.tr/uploads/jtn-31732-video-3.mp4

\section{ABSTRACT}

AIM: To introduce a traumatic brain injury (TBI) patient who underwent stem cell transplantation (SCT) in order to minimize the remaining injury deficiencies.

MATERIAL and METHODS: This study included a 29 years old male who had TBI resulting from a vehicle accident which took place one and a half years ago. The participant received six doses of intrathecal, intramuscular, and intravenous transplantation of Wharton's jellv-derived mesenchymal stem cells (WJ-MSCs) at a goal dose of $1 \mathrm{xI}^{6} / \mathrm{kg}$ respectively for each route of administration for six months.

RESULTS: No important negative effects were reported. The patients' speech, cognitive, memory and fine motor skills were improved. The efficacy of treatment with SCT was assessed with cranial magnetic resonance imaging (MRI), computed tomography (CT) screening, and electroencephalography (EEG).

CONCLUSION: SCT can have a promising future as a medical approach in recurrent TBI.

KEYWORDS: Stem cell, Brain injury, Umbilical cord, Transplantation

ABBREVIATIONS: a.f.i.: After the first intervention, CNS: Central nervous system, CT: Computed tomography, DC: Decompressive craniectomy, EEG: Electroencephalogram, FIM: Functional independence measure, i.m: Intramuscular, i.t: Intrathecal, i.v.: Intravenous, MRI: Magnetic resonance imaging, MRC: Medical Research Council, MSCs: Mesenchymal stem cells, NeDs: Neurological disorders, Pre-t.p: pre-transplantation, PTH: Post-traumatic hydrocephalus, SCT: Stem cell therapy, VP: Ventriculoperitoneal, WJ-MSCs: Wharton's jellv-derived mesenchymal stem cells

Serdar KABATAS (D) : 0000-0003-2691-6861

Erdinc CIVELEK (D) : 0000-0002-3988-4064

Gulseli Berivan SEZEN (D) : 0000-0001-9129-5470
Necati KAPLAN

(D) : 0000-0001-5672-0566

Eyup Can SAVRUNLU (D) : 0000-0001-9022-200X

Ercan CETIN
Furkan DIREN (D) : 0000-0001-6169-9722

Erdal KARAOZ (D) : 0000-0002-9992-833X 
Kabatas S. et al: Mesenchymal Stem Cells and TBI

\section{INTRODUCTION}

T raumatic brain injury (TBI) is a prominent public health and socioeconomic issue (12). It is described as "a brain function change or other signs of brain pathology that is induced by an external force" (15). It may lead to brain parenchyma after a head trauma and result in neurological deficiencies (5). It is regarded as a "silent disease" since the severity of the outcomes of this disease is not entirely understood yet (17). Nearly $50 \%$ of TBls were reported to source from motor vehicle accidents.

$\mathrm{TBI}$ is also caused by acts of violence, explosions, falls and sports injury (10). TBI is usually related to short period of concentration, mood disturbances, bad decision-making and physical disability (17). Cerebral injury following TBI causes immediate harm to the tissue and changes cerebral blood flow control and metabolism and this provokes a series of neurochemical alterations and leads to apoptosis (25). Focusing on a multidisciplinary strategy is crucial because of insufficient treatment methods of persistent TBI. Stem cell therapy (SCT) is an inventive procedure capable of supplementing or substituting medicinal and surgical therapies (3). This innovative technique seeks to prevent neuronal degeneration and replace the damaged neurons. Stem cells are capable of differentiating and transforming into mature cells, thereby restoring the damaged cells $(9$, 24). Several preclinical studies indicated the SCT to be secure and effective in the management of TBI $(2,13)$. In addition, numerous sources of cells for transplantation, such as mesenchymal stem cells; were used in clinical studies for TBI (MSCs; e.g., Wharton's jelly-derived MSCs [WJ-MSCs]). MSCs help recover the injured tissues which occur due to TBls resulting from the bystander effect. MSCs may be led by chemotaxis or an inflammatory element, move to the region of lesion, preferably let go the nutritional factors and perform the role of antiapoptosis. Simultaneously, WJ-MSCs have unique benefits such as being plentiful, simple to acquire with minimum invasiveness, and readily cultured to a reasonable amount for transplantation without the ethical problems which are characteristic to allografting. We formerly assessed the security and usefulness of both the triple route and multiple WJ-MSC implantations in treating a patient with hypoxicischemic encephalopathy (HIE) (7). In the present study, we introduced an incident of a 29-year-old male who was struggling with $\mathrm{TBI}$ as a consequence of a road accident. The patient underwent intrathecal (i.t.), intramuscular (i.m.), and intravenous (i.v.) WJ-MSC transplantation one and a half years following his $\mathrm{TBI}$ to minimize the remaining injury deficiencies.

\section{CASE PRESENTATION}

The pilot study introduced was a prospective, longitudinal medical experiment. The study was conducted in Health Sciences University, Gaziosmanpaşa Training and Research Hospital, Istanbul, Turkey. The Turkish ministry of health approved the MSC trial (protocol number: 56733164-203E.2569). Legal counselors of the patient were informed of the operation, and a written informed consent form was acquired according to the Helsinki Declaration. The general data gathered prior to the experimental therapy included age, sex, reasons for TBI, span of time after the TBI, previous TBI medical care and medical history.

\section{Medical History}

The patient was a 29-year-old man that experienced a motor vehicle crash and had a serious TBI in March 2017. He underwent decompressive craniectomy (DC) and ventriculoperitoneal (VP), and a couple months after, his craniectomy flap was placed back on his skull. He was conscious but did not respond, tetraplegic with high-degree muscle spasms, and could not speak, control his sphincter and communicate. He completed almost a year in a rehabilitation clinic but did not show much progress. Injections of botulinum toxin against muscle spasms provided only partial relief. His upper extremities were hyperflexed in a decorticated pose, and his lower extremities stretched. His muscle tone was improved, and the everyday tasks such as mobilization and bathing became considerably difficult. At this point, the patient was referred for the MSC trial at our tertiary-level hospital.

\section{Enrollment Criteria}

The participant, whose TBI was verified by imaging tests (including a computed tomography (CT) scan), neurological examination, and neurophysiological observations electroencephalography (EEG); was included the pilot study. Those who had focal central nervous system (CNS) lesions (e.g., neoplastic lesions) and chronic disorders (e.g., systemic disorders) involving long term pharmacotherapy were excluded from the study. The patient was assessed by the physicians in the units of neurosurgery and physical therapy and rehabilitation. The WJ-MSC implantation process was conducted when the patient was stable, without potential side effects for sedo-/general anesthesia in terms of internal medicine and any significant infectious illnesses including sepsis.

\section{PROCEDURE}

Umbilical cords were collected from LivMedCell's (Istanbul, Turkey) Good Manufacturing Practice facility. Upon receiving informed consent, all the umbilical cords were collected from different donors, as authorized by the LivMedCell institutional regulatory board. Postnatal umbilical cords were collected from patients who underwent full-term gestation. Our recent publications included the processing and quality testing of umbilical cords, description of WJ-MSCs by flow cytometry, cell differentiation and karyotyping, the pre-transplantation process, and surgical and WJ-MSC transplantation (Table I) $(7,16)$.

\section{口 CLINICAL ASSESSMENT}

\section{Pre-treatment Neurological Investigation}

The pre-treatment evaluation required a thorough review by a group of medical and rehabilitation professionals (Suppl. Video 1). For each phase of the protocol, comprehensive neurological and functional assessments were recorded. Spasticity was evaluated through the Updated Ashworth Scale (MAS), and quality of life was evaluated according to the 
Kabatas S. et al: Mesenchymal Stem Cells and TBI

Table I: WJ-MSC Administration Schedule

\begin{tabular}{lcc}
\hline Date & Route & WJ-MSC \\
\hline Round 1 & & \\
\hline 24.09 .2018 & IT & $1 \times 10^{6} / \mathrm{kg}$ in $3 \mathrm{ml}$ \\
\hline 24.09 .2018 & IV & $1 \times 10^{6} / \mathrm{kg}$ in $30 \mathrm{ml}$ \\
\hline 24.09 .2018 & IM & $1 \times 10^{6} / \mathrm{kg}$ in $20 \mathrm{ml}$ \\
\hline
\end{tabular}

Round 2

\begin{tabular}{lll}
\hline 09.10 .2018 & IT & $1 \times 10^{6} / \mathrm{kg}$ in $3 \mathrm{ml}$ \\
\hline 09.10 .2018 & IV & $1 \times 10^{6} / \mathrm{kg}$ in $30 \mathrm{ml}$ \\
\hline 09.10 .2018 & IM & $1 \times 10^{6} / \mathrm{kg}$ in $20 \mathrm{ml}$ \\
\hline
\end{tabular}

Round 3

\begin{tabular}{lll}
\hline 09.11 .2018 & IT & $1 \times 10^{6} / \mathrm{kg}$ in $3 \mathrm{ml}$ \\
\hline 09.11 .2018 & IV & $1 \times 10^{6} / \mathrm{kg}$ in $30 \mathrm{ml}$ \\
\hline 09.11 .2018 & IM & $1 \times 10^{6} / \mathrm{kg}$ in $20 \mathrm{ml}$ \\
\hline
\end{tabular}

Round 4

\begin{tabular}{lll}
\hline 17.12 .2018 & IT & $1 \times 10^{6} / \mathrm{kg}$ in $3 \mathrm{ml}$ \\
\hline 17.12 .2018 & IV & $1 \times 10^{6} / \mathrm{kg}$ in $30 \mathrm{ml}$ \\
\hline 17.12 .2018 & IM & $1 \times 10^{6} / \mathrm{kg}$ in $20 \mathrm{ml}$ \\
\hline
\end{tabular}

\section{Round 5}

\begin{tabular}{lll}
\hline 07.01 .2019 & IT & $1 \times 10^{6} / \mathrm{kg}$ in $3 \mathrm{ml}$ \\
\hline 07.01 .2019 & IV & $1 \times 10^{6} / \mathrm{kg}$ in $30 \mathrm{ml}$ \\
\hline 07.01 .2019 & IM & $1 \times 10^{6} / \mathrm{kg}$ in $30 \mathrm{ml}$ \\
\hline
\end{tabular}

\section{Round 6}

\begin{tabular}{lll}
\hline 07.02 .2019 & IT & $1 \times 10^{6} / \mathrm{kg}$ in $3 \mathrm{ml}$ \\
\hline 07.02 .2019 & IV & $1 \times 10^{6} / \mathrm{kg}$ in $30 \mathrm{ml}$ \\
\hline 07.02 .2019 & IM & $1 \times 10^{6} / \mathrm{kg}$ in $30 \mathrm{ml}$ \\
\hline
\end{tabular}

IT: Intratekal, IV: Intravenous, IM: Intramuscular, WJ-MSC: Wharton's Jelly-Derived Mesenchymal Stem Cell.

parental assessment of Functional Independence Measure (FIM) scale.

\section{Safety Assessment Criteria}

The patient required to be free of inflammation, fever, elevated rates of C-reactive protein, elevated leukocytosis, allergic reactions / shock, and perioperative complications (anesthesia-and analgesia-related problems and/or wound infections) for seven to 14 days following the procedure to be safe for the transplantation. WJ-MSC could be used only if infection, neuropathic discomfort, cancer growth and cognitive impairment was absent and these criteria were evaluated for one year after the procedure.

\section{Follow-up Evaluation of Treatment Success}

The follow-up assessment comprised of a neurological test of muscle control, spasticity and quality of life. The muscle activity was measured by the Medical Research Council (MRC) Muscle Strength Scale. Spasticity was evaluated with the Updated Ashworth Scale and the quality of life was assessed based on the functional healing calculated by the FIM Scale (21). The incidence of neuropathic pain, secondary infections, urinary tract infections, and/or pressure ulcers on the skin were also assessed.

\section{RESULTS}

\section{Safety and Adverse Effects}

The participant endured the process excellently and did not have any serious injection related side effects. Our patient had only early, temporary complications such as subfebrile fever, moderate headache, and muscle pain related to i.m. injection which was settled by symptomatic medical care within 24-48 hours (Table II). No other safety problems or negative effects were identified during the one-year follow-up (Figure 1A, Table IV).

\section{FIM Scale Score}

The six item FIM Scale (e.g. self-care, along with the motor and cognitive ratings) showed important developments in the participant's quality of life. The total FIM Scale score changed from 22/126 at baseline to 76/126 in 12 months.

\section{Modified Ashworth and MRC Muscle Strength Scale}

The Modified Ashworth Scale total score was similar on both sides. This scale was used to assess the shoulders, elbows, hips, knees and ankles which improved from 44 at baseline to 16 in 12 months. Likewise, the total score for the MRC Muscle Strength Measure also increased on both sides including the hands, arms, elbows, wrists, knees and ankles, from 22 at baseline to 44 during the one-year follow-up (Figure 1B, C; Table III).

\section{Neuroradiological and Neurophysiological Findings}

The former postoperative cranial CT and MRI demonstrated encephalomalacic sequelae and hydrocephalus with VP shunting. Prior to and following each transplantation, we carried out repeat cranial CTs to test the advancement of the patient's hydocephalus thoroughly.

No substantial difference was found between the current and past cranial CT results 12 months after the first intervention (a.f.i.) (Figure 2A-E; Table V). The pre-transplantation EEG showed unorganized waveform patterns which suggested widespread brain injury. Following the $6^{\text {th }}$ transplantation, the patient's EEG additionally showed disorganized waveform patterns (Table V).

\section{Physical Therapy and Rehabilitation}

There was a significant clinical development in the patient's reaction to physical therapy during the follow-up. He underwent in-depth neurorehabilitation with physiotherapy a.f.i. he was 
Table II: Early and Late Complications of the Procedures

\begin{tabular}{|c|c|c|c|c|c|c|}
\hline Date & 24.09.2018 & 09.10 .2018 & 09.11 .2018 & 17.12.2018 & 07.01 .2019 & 07.02.2019 \\
\hline \multicolumn{7}{|l|}{ Early } \\
\hline Infection & - & - & - & - & - & - \\
\hline Fever & + & + & - & + & - & - \\
\hline Pain & + & - & + & + & - & - \\
\hline Headache & + & + & - & - & - & - \\
\hline Increased level of C-reactive protein & - & - & - & - & - & - \\
\hline Leukocytosis & - & - & - & - & - & - \\
\hline Allergic reaction/shock & - & - & - & - & - & - \\
\hline Perioperative complications & - & - & - & - & - & - \\
\hline \multicolumn{7}{|l|}{ Late } \\
\hline Secondary infections & - & - & - & - & - & - \\
\hline Urinary tract infections & - & - & - & - & - & - \\
\hline Deterioration of neurological status & - & - & - & - & - & - \\
\hline Neuropathic pain & - & - & - & - & - & - \\
\hline Carcinogenesis & - & - & - & - & - & - \\
\hline
\end{tabular}

Table III: Quality-of-Life Improvement (Motor and Cognitive Scores), Spasticity, and Motor Function Evaluated with the Use of the FIM Scale, Modified Ashworth Grading and MRC Muscle Strength Scale

Evaluation

Periods (Pre and Post-transplantation)

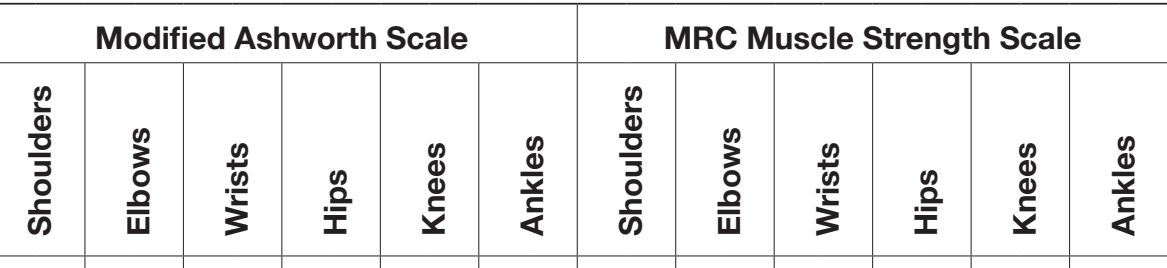

\begin{tabular}{lccc|cc|cc|cc|cc|cc|cc|cc|cc|cc|ccc|cc|ccc}
\hline & Motor & Cognitive & $\mathbf{R}$ & $\mathbf{L}$ & $\mathbf{R}$ & $\mathbf{L}$ & $\mathbf{R}$ & $\mathbf{L}$ & $\mathbf{R}$ & $\mathbf{L}$ & $\mathbf{R}$ & $\mathbf{L}$ & $\mathbf{R}$ & $\mathbf{L}$ & $\mathbf{R}$ & $\mathbf{L}$ & $\mathbf{R}$ & $\mathbf{L}$ & $\mathbf{R}$ & $\mathbf{L}$ & $\mathbf{R}$ & $\mathbf{L}$ & $\mathbf{R}$ & $\mathbf{L}$ & $\mathbf{R}$ & $\mathbf{L}$ \\
\hline Pre-Transplantation & 13 & 9 & 3 & 3 & 4 & 4 & 4 & 4 & 4 & 4 & 4 & 4 & 3 & 3 & 2 & 2 & 2 & 2 & 2 & 2 & 2 & 2 & 2 & 2 & 1 & 1 \\
\hline $1^{\text {st }}$ week & 14 & 15 & 3 & 3 & 3 & 3 & 3 & 4 & 4 & 3 & 3 & 4 & 3 & 3 & 3 & 2 & 2 & 2 & 2 & 2 & 2 & 2 & 3 & 3 & 2 & 2 \\
\hline $1^{\text {st }}$ month & 19 & 18 & 2 & 3 & 2 & 3 & 3 & 3 & 3 & 3 & 3 & 3 & 3 & 3 & 3 & 3 & 3 & 3 & 3 & 2 & 3 & 3 & 3 & 3 & 3 & 3 \\
\hline $2^{\text {nd }}$ month & 30 & 22 & 2 & 2 & 2 & 2 & 2 & 3 & 2 & 3 & 2 & 3 & 2 & 3 & 3 & 3 & 4 & 3 & 3 & 3 & 3 & 3 & 4 & 3 & 3 & 3 \\
\hline $3^{\text {rd }}$ month & 40 & 27 & 1 & 2 & 2 & 2 & 2 & 2 & 2 & 2 & 1 & 2 & 2 & 2 & 4 & 4 & 4 & 3 & 4 & 3 & 4 & 4 & 3 & 3 & 3 & 3 \\
\hline $1^{2^{\text {th }} \text { month }}$ & 46 & 30 & 1 & 1 & 1 & 2 & 1 & 1 & 1 & 2 & 1 & 1 & 2 & 2 & 4 & 4 & 4 & 4 & 4 & 4 & 4 & 4 & 3 & 3 & 3 & 3 \\
\hline
\end{tabular}

FIM: Functional Independence Measurement, MRC: Medical Research Council, R: Right, L: Left.

prescribed a target exercise schedule that stressed methods to improve mobility and the multiplication of the injected stem cells, hence, he had better outcomes. The target schedule lasted 50 minutes per day, repeated five times a week and contained posture, balance, range of motion, strength, and stretch exercises. The exercise program was discontinued on the days of stem cell administration. The patient responded upon the first transplantation to external stimuli and such an improvement was highly valued by his mother and the caregivers. He could stand on his feet with support, move one foot backwards to enhance his balance and his muscle spasms were reduced after the third transplantation (Suppl. Video 2). His social skills and independent movements (e.g. independently kissing the hands of a caregiver) were improved after the fourth transplantation. Moreover, he could stand on his feet with less support after the intensive exercise program 


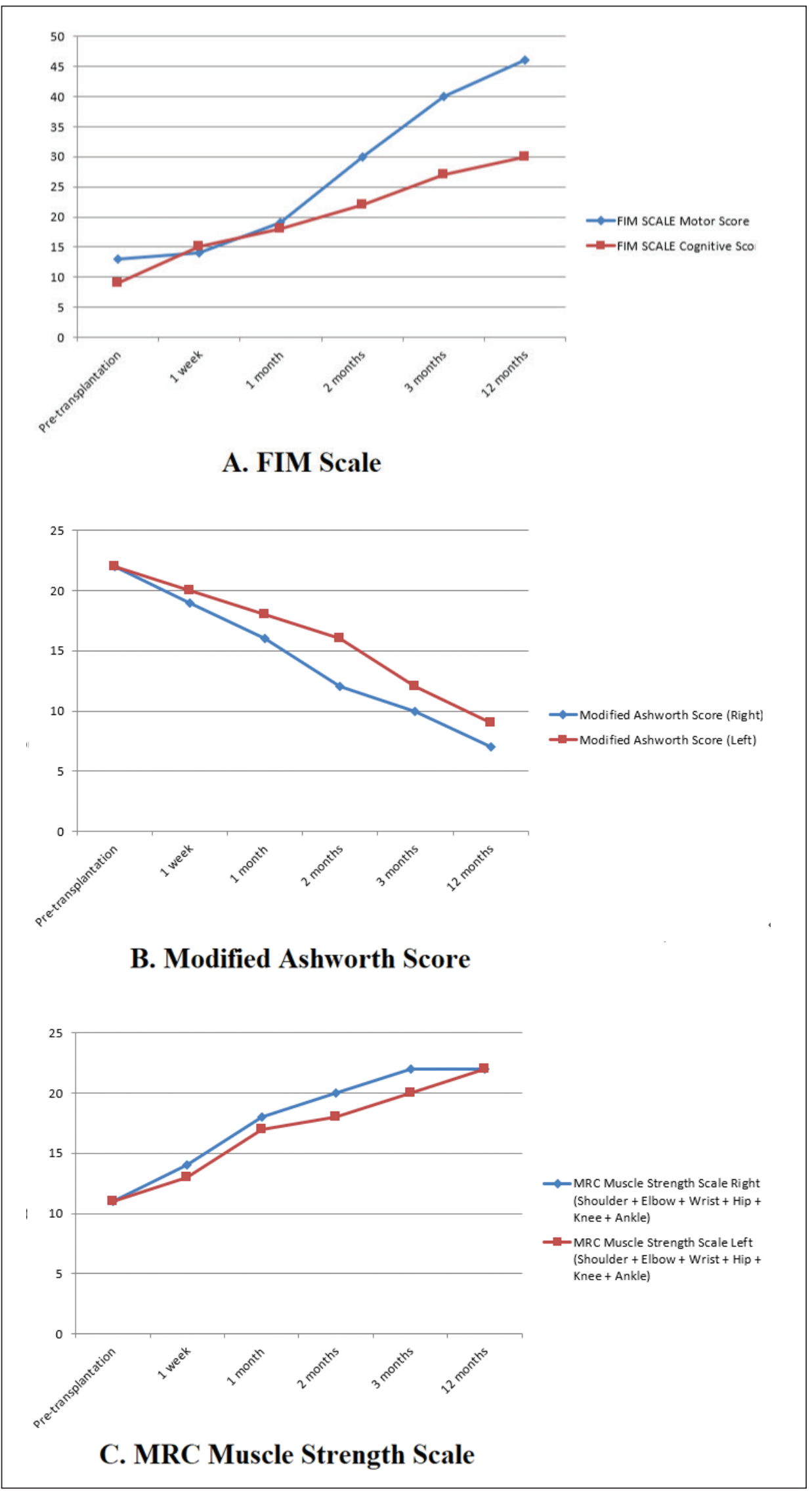

Figure 1: The progress of patient's quality of life (motor and cognitive scores), spasticity, and motor were assessed through FIM (A), Modified Ashworth Grading (B), and MRC Muscle Strength (C) scale in graphics, respectively. 
Table IV: Quality-of-life Improvement Evaluated with the Use of the FIM Scale

\section{Measurement}
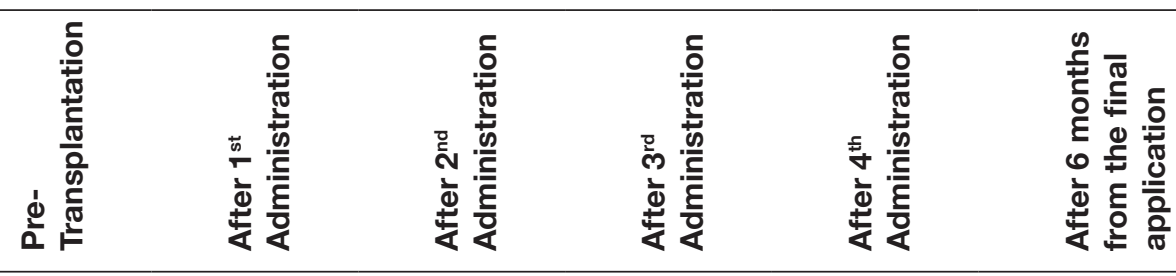

\section{Self-Care}

\begin{tabular}{lllllll}
\hline Eating & 1 & 1 & 3 & 5 & 5 & 4 \\
\hline Grooming & 1 & 1 & 1 & 3 & 3 & 4 \\
\hline Bathing & 1 & 1 & 2 & 2 & 3 & 4 \\
\hline Dressing-Upper body & 1 & 1 & 1 & 1 & 2 \\
\hline Dressing-Lower body & 1 & 1 & 1 & 3 \\
\hline
\end{tabular}

2. Toileting (Sphincter Control)

\begin{tabular}{lllllll}
\hline Bladder Management & 1 & 1 & 1 & 1 & 3 & 4 \\
\hline Bowel Management & 1 & 1 & 1 & 1 & 2 & 2 \\
\hline
\end{tabular}

\section{Transfer}

\begin{tabular}{lllllll}
\hline Bed, Chair, Wheelchair & 1 & 1 & 3 & 5 & 5 & 5 \\
\hline Toilet & 1 & 1 & 1 & 2 & 3 & 2 \\
\hline Tub, Shower & 1 & 1 & 1 & 1 & 3 \\
\hline
\end{tabular}

\section{Locomotion}

\begin{tabular}{lrrrrrr}
\hline Walk/Wheelchair & 1 & 2 & 3 & 5 & 5 & 5 \\
\hline Stairs & 1 & 1 & 1 & 1 & 2 & $\mathbf{4 0}$ \\
\hline Motor Subtotal Score & $\mathbf{1 3}$ & $\mathbf{1 4}$ & $\mathbf{1 9}$ & $\mathbf{3 0}$ & $\mathbf{4 6}$ \\
\hline
\end{tabular}

\section{Communication}

\begin{tabular}{lllllll}
\hline Comprehension & 3 & 5 & 5 & 6 & 7 & 7 \\
\hline Expression & 2 & 3 & 4 & 4 & 5 & 5 \\
\hline
\end{tabular}

\section{Social Cognition}

\begin{tabular}{|c|c|c|c|c|c|c|}
\hline Social Interaction & 2 & 3 & 4 & 5 & 6 & 7 \\
\hline Problem Solving & 1 & 1 & 2 & 3 & 4 & 5 \\
\hline Memory & 2 & 3 & 3 & 4 & 5 & 7 \\
\hline Cognitive Subtotal Score & 9 & 15 & 18 & 22 & 27 & 30 \\
\hline Total FIM Score & 23 & 29 & 37 & 52 & 67 & 76 \\
\hline
\end{tabular}

FIM: Functional Independence Measurement. FIM scale in detail: 7 Points = Complete Independence, 6 Points = Modified Independence, 5 Points = Supervision, 4 points = Minimal Assistance, 3 Points = Moderate Assistance, 2 Points = Maximal Assistance, and 1 Point = Total Assistance or not Testable.

Total motor score: 91 points, Total cognitive score: 35 points, and Total FIM score: 126 points.

following the fifth transplantation (Suppl. Video 3). He tried to talk and utter following the sixth transplantation sounds (Suppl. Video 4). The patient had follow-ups every six months to evaluate his progress further.

\section{DISCUSSION}

Cerebral injury following TBI leads to ischemia of the cerebral tissue, thereby, results in anaerobic glycolysis. Such incidents cause membrane deterioration of vascular and 
Kabatas S. et al: Mesenchymal Stem Cells and TBI

Table V: Summary of the Neuroradiological and Neurophysiological Findings Using Cranial CT and EEG Before and After the Treatment

\begin{tabular}{lll}
\hline CT & Date & CT Appearance of Cranium \\
\hline & Pre-t.p. & $\begin{array}{l}\text { Dilation in the lateral ventricle. } \\
\text { Focal encephalomalacic appearance in the right temporal and bilateral frontal lobe. }\end{array}$ \\
\hline PEG & Dost-t.p. & No significant difference between the findings compared to the previous CT. \\
\hline & Pre-t.p. & EEG Findings \\
\hline & Post-t.p. & Disorganized waveform pattern. \\
\hline
\end{tabular}

CT: Computed tomography, EEG: Electroencephalogram, t.p: Transplantation.
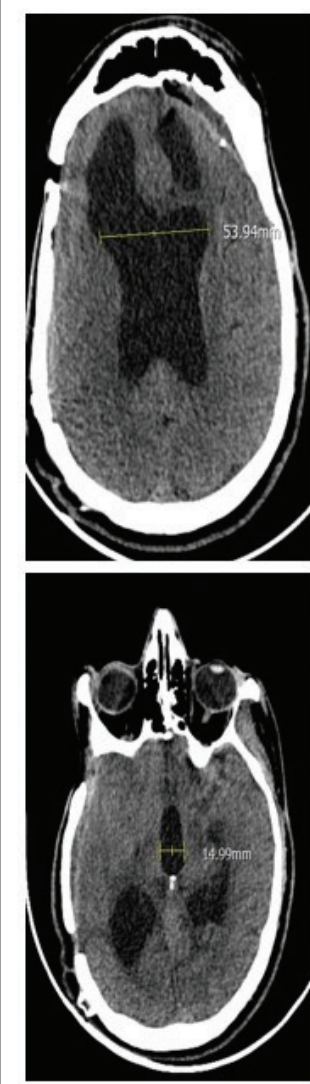

\section{A. Pre-t.p}
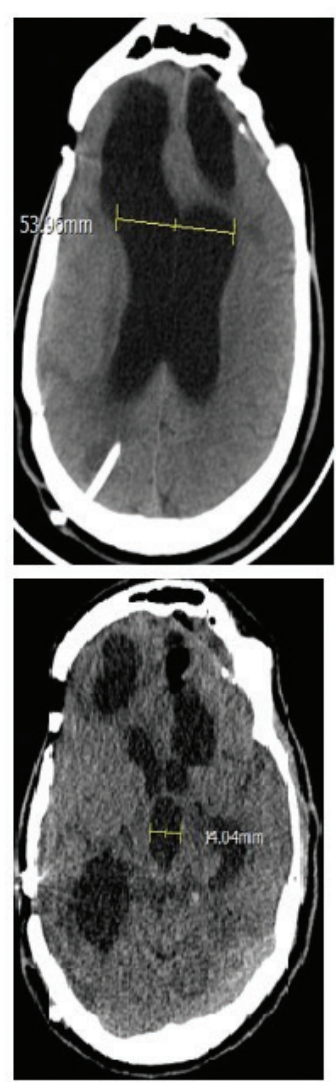

B. 1 week
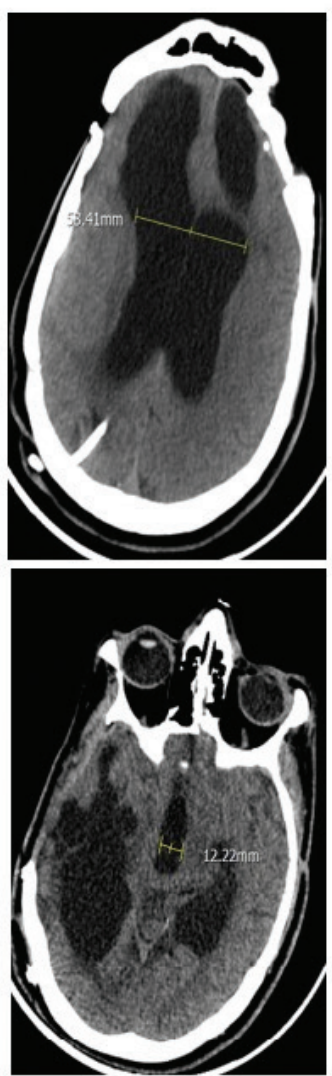

C. 2 months
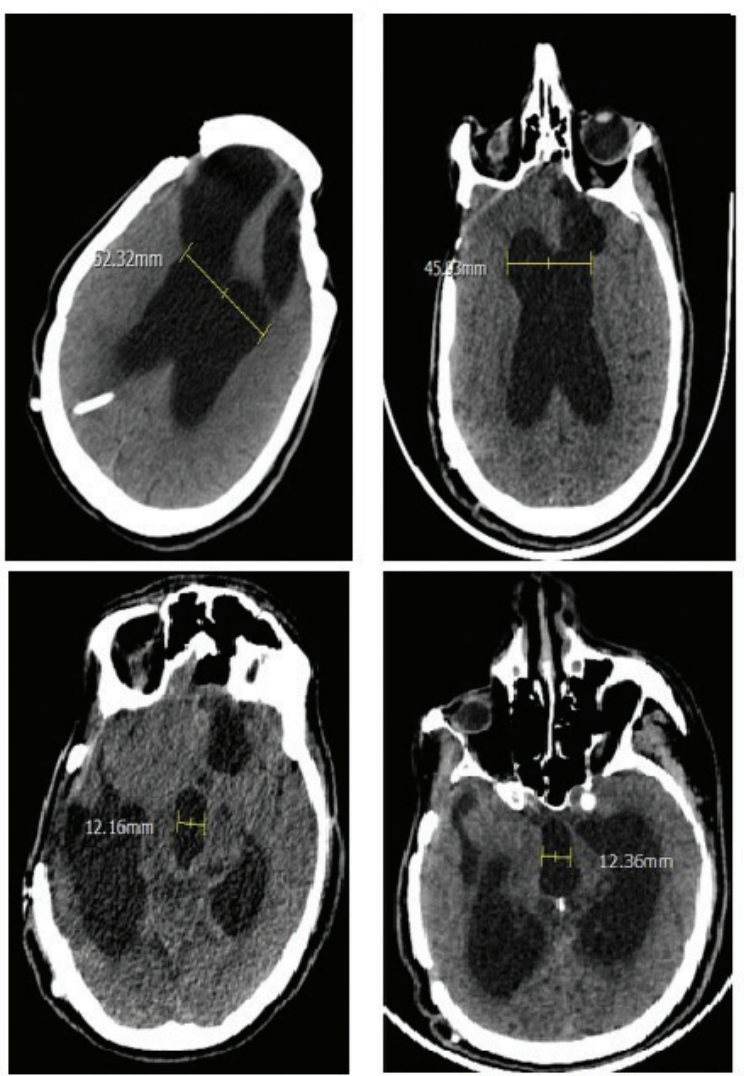

D. 4 months

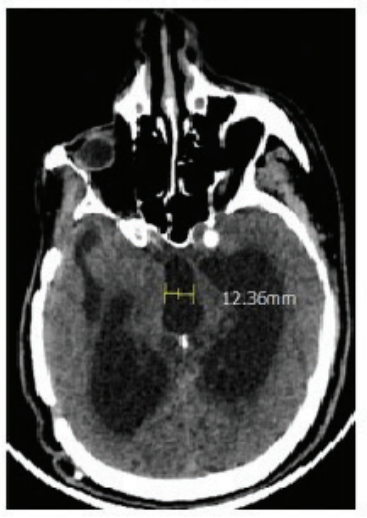

E. 12 months

Figure 2: The former postoperative cranial CT demonstrated encephalomalacic sequelae and hydrocephalus with VP shunting (A). Repeated cranial CTs on the first week (B), second month (C), third month (D), and $12^{\text {th }}$ month (E) after the first intervention.

cellular forms in the cerebral tissue, consequently, cause necrosis and apoptosis (22). DC treatment and diverse pharmacological medications are recommended to manage TBI (4,14). Regardless, such therapeutic interferences do not cease the neuronal deterioration. In other respects, SCT has a rare ability to change the development of the illness, as stem cells can alter and grow into mature and multipotent cells (24). TBI includes diffused axonal injury and the myelin sheath is interrupted, therefore, it has an effect on the neurotransmission (26). Stem cells home in on and migrate to the injury site, thereby reducing inflammation by mediating inflammatory markers (19). Moreover, these cells change and generate into neural cells and oligodendrocytes that lead to remyelination of the damaged axons and enhance neural pathways (18). Neuroprotection and neuroangiogenesis are caused by the release of numerous elements such as brain-derived neurotrophic factor (BDNF) from these stem cells (20). Additionally, immune cells and cytokines caused 
by cerebral inflammatory responses TBI can be modulated by MSCs. Hence, SCT provides fresh perspectives into the immunomodulatory mechanisms that are caused by MSC transplantation by implying useful neurological healing following TBI (26). Preclinical studies utilized numerous kinds of stem cells and various routes of administration while treating TBI $(2,13)$. Therefore, cell transplantation may enhance functional results following TBI.

In the present study, we applied triple route (i.v., i.t, and i.m.) and multiple WJ-MSCs to the patient. WJ is a valuable source of stem cells that are utilized in various animal models of neurological disorders (NeDs). WJ-MSCs were preferred since they were safe and could be isolated without difficulty. WJ-MSCs which is a rich source of HLA-G has an immunosuppressive effect on natural killer-cells and T-cells. This expression profile is significant when preventing maternal immunity against the fetus during gestation and supplying superior graft acceptance in SCT. WJ-MSCs are excellent cell sources for third-party/ allogeneic administrations due to HLA-G secretion. The latest clinical trials suggest the administration of WJ-MSC is favorable for patients with NeDs such as TBI (7).

There are numerous clinical studies conducted worldwide indicating the cellular therapy to be secure and efficient in TBI. Nonetheless, the targeted route stem cell transplantation becomes increasingly popular. Stem cells in the target area should be highly concentrated to magnify the advantages of cellular transplantation. So, cells should be transplanted in the regional routes (20). Intracerebral transplantation may be optimal in TBI however, this intrusive procedure may also cause secondary harm to the cerebral tissue. Administration of stem cells through i.t. enhances neural connectivity, reduces pro-inflammatory mediators in the brain and spinal cord, and increases the movement and distinction of neural precursors (22). Moreover, Sharma et al. found that i.t. transplantation of autologous bone marrow MSCs helped the functional healing of neurological deficiency and increased the living standards of those who suffer from TBI (18). Additionally, numerous studies indicated that only i.v. transplantation was completely effective while treating TBI $(11,20)$. Nevertheless, i.v. transplantation may confine the administrated cells in the lungs and cause inadequate number of cells in the target area to deliver favorable TBI outcomes (1). We formerly discussed the security and usefulness of the triple route and multiple WJ-MSC implantations in HIE and cerebral palsy. In this pilot study, the patient received combined (i.v., i.t., and i.m.) WJMSC transplantation that lasted six months. These routes are minimally intrusive and targeted the favored area.

The participant demonstrated changes in his speech, mental skills, ability to focus, concentrating, short-term memory and fine and gross motor movements in our present case report. His degree of autonomy has increased, as demonstrated by the one-year follow-up improvement of his FIM motor scale score from 13/91 at baseline to 46/91. His cognitive score progress was much higher than his motor score, improving from $9 / 35$ at baseline to $27 / 35$ on the third month follow-up. His cognitive score was $30 / 35$, at the last follow-up. While this was a pilot study, as reported in trials of MSC-treated HIE and $\mathrm{CP}$ patients, the clinical results of MSCs indicated that they affected cognitive functions before motor functions $(7$, 16). In fact, care including SCT along with physiotherapy has astounding benefits for people with neurological conditions due to incidents such as TBI. The therapy alone may stop the progression of muscle atrophy and joint stiffness; however, the impaired nerve function cannot be restored (8). It is believed that such a change could be due to the transfer of MSCs to the injury site and the development of neuroregenerative mechanisms there. Additionally, findings also suggested that successful therapy practices could partly recover the impaired nerve activity within the first year of TBI. Nonetheless, the latest standard therapy procedures have minimal advantages for individuals who lived with TBls over a year (23). In the present report, we provided both subjective (physical therapy and rehabilitation reports) and objective (FIM, Modified Ashworth and MRC Muscle Strength Scales scores) tests to show that the participant achieved an increase in neurological and functional performance after a reaching a plateau of spontaneous improvement one and a half years post-injury.

The patient's neurophysiological follow-ups showed abnormal waveform patterns which suggested extensive brain injury in the EEG similar to the findings before the procedure, however there was no increase in epileptic attacks of the patient; rather, the patient had less epileptic attacks and the dosage of antiepileptic treatment was decreased in the follow-ups. Particularly, MSC implantation usually decreases seizures and protects the neurons more excellently (6). Therefore, while the EEG monitoring of the patient did not dramatically change, the decrease in the epileptic attacks may prove the advantages of treatment with MSC.

Post-traumatic hydrocephalus (PTH) has an effect on 19$36 \%$ of patients undergoing $\mathrm{DC}$ and is a significant reason for morbidity following TBI. Hydrocephalus usually occurs about a month after a patient has DC and can be linked with worse results. Early detection and care of PTH (through, for example, VP shunting) in patients recovered from TBI will stop more neurological deterioration (22). There were no studies on the impact stem cells had on hydrocephalus. So, intracranial hypertension might be increased by stem cells but as it's observable in the cranial CT follow-up results, such an incidence did not take place in our case. Particularly, the patient's adjustable shunt pressure did not require any alterations in the follow-up. So, these findings indicated that SCT did not have a direct effect on the progression of hydrocephalus.

\section{CONCLUSION}

This case study demonstrated that cell transplantation might be greatly beneficial in the treatment of TBI. Through such a method, the feasible neurons might be protected and the damaged ones could be changed by the neuroprotection and neuroangiogenesis mechanisms. Cellular transplantation, in addition to neurorehabilitation, has a significant role in the functional healing of chronic TBI patients and increasing their standard of living. A thorough comparative study including 
different types of cells and routes of transplantation should be carried out. Methodologically rigorous studies with randomization, blinding strategies, and control groups should be carried out to reach more definite results.

\section{REFERENCES}

1. Fischer UM, Harting MT, Jimenez F, Monzon-Posadas WO, Xue, $\mathrm{H}$ : Pulmonary passage is a major obstacle for intravenous stem cell delivery: The pulmonary first-pass effect. Stem Cells Dev 18:683-692, 2009

2. Galindo LT, Filippo TRM., Semedo P, Ariza CB, Moreira CM, Camara NOS, Porcionatto MA: Mesenchymal stem cell therapy modulates the inflammatory response in experimental traumatic brain injury. Neurol Res Int 2011:564089, 2011

3. Gang LI, Yang Y, Dong H, Lin L: The research progress of mesenchymal stem cells in the treatment of traumatic brain injury. Turk Neurosurg 28(5):696-702, 2018

4. Ghajar, J: Traumatic brain injury. Lancet 356:923-929, 2000

5. Heegaard W, Biros M: Traumatic brain injury. Emerg Med Clin North Am 25:655-678, 2007

6. Hlebokazov F, Dakukina T, Ihnatsenko S, Kosmacheva S, Potapnev M, Shakhbazau A, Goncharova N, Makhrov M, Korolevich P, Misyuk N, Dakukina V, Shamruk I, Slobina E, Marchuk S: Treatment of refractory epilepsy patients with autologous mesenchymal stem cells reduces seizure frequency: An open label study. Adv Med Sci 62(2):273-279, 2017

7. Kabatas S, Civelek E, İnci C, Yalcinkaya EY, Gunel G, Kir G, Albayrak E, Ozturk E, Adas G, Karaoz E: Wharton's jellyderived mesenchymal stem cell transplantation in a patient with hypoxic-ischemic encephalopathy: A pilot study. Cell Transplant 27(10):1425-1433, 2018

8. Kamelska-Sadowska AM, Wojtkiewicz J, Kowalski IM: Review of the current knowledge on the role of stem cell transplantation in neurorehabilitation. Biomed Res Int 25:3290894, 2019

9. Kim JJ, Gean AD: Imaging for the diagnosis and management of traumatic brain injury. Neurotherapeutics 8:39-53, 2011

10. Langlois JA, Rutland-Brown W, Wald MM: The epidemiology and impact of traumatic brain injury: A brief overview. J Head Trauma Rehabil 21:375-378, 2006

11. Liao G, Harting M, Hetz R, Walker PA, Do SKS, Corkins CJ, Hughes TG, Jimenez F, Kosmach SC, Day MC, Tsao KJ, Lee DA, Worth LL, Baumgartner JA, Cos CS: Autologous bone marrow mononuclear cells reduce therapeutic intensity for severe traumatic brain injury in children. Pediatr Crit Care Med 16:245-255, 2015

12. Maas Al, Stocchetti N, Bullock R: Moderate and severe traumatic brain injury in adults. Lancet Neurol 7:728-741, 2008

13. Mahmood A, Lu D, Lu M, Chopp M: Treatment of traumatic brain injury in adult rats with intravenous administration of human bone marrow stromal cells. J Neurosurg 53:693-702, 2003
14. McKintosh T: Novel pharmacologic therapies in the treatment of experimental traumatic brain injury: A review. J Neurotrauma 10:215-261, 2009

15. Menon DK, Schwab K, Wright DW, Maas Al: Demographics and clinical assessment working group of the international and interagency initiative toward common data elements for research on traumatic brain injury and psychological health, position statement: Definition of traumatic brain injury. Arch Phys Med Rehabil 91:1637-1640, 2010

16. Okur SC, Erdogan S, Demir CS, Gunel G, Karaoz E: The effect of umbilical cord-derived mesenchymal stem cell transplantation in a patient with cerebral palsy: A case report. Int J Stem Cells 11(1):141-147, 2018

17. Roozenbeek B, Maas Al, Menon DK: Changing patterns in the epidemiology of traumatic brain injury. Nat Rev Neurol 9:231236, 2013

18. Sharma A, Sane H, Kulkarni P, Yadav J, Gokulchandran N, Biju $\mathrm{H}$, Badhe P: Cell therapy attempted as a novel approach for chronic traumatic brain injury: A pilot study. Springerplus 4:26, 2015

19. Sharma A, Sane H, Paranjape A, Gokulchandran N, Nagrajan A, D'sa M, Badhe PB: The effect of autologous bone marrow mononuclear cell transplantation on the survival duration in amyotrophic lateral sclerosis: A retrospective controlled study. Am J Stem Cells 4:50-65, 2015

20. Strauer BE, Kornowski R: Stem cell therapy in perspective. Circulation 107:929-934, 2003

21. Thorpe ER, Garrett KB, Smith AM, Reneker JC, Phillips RS: Outcome measure scores predict discharge destination in patients with acute and subacute stroke: A systematic review and series of meta-analyses. J Neurol Phys Ther 42(1):2-11, 2018

22. Vedantam A, Yamal JM, Hwang H, Robertson CS, Gopinath SP: Factors associated with shunt-dependent hydrocephalus after decompressive craniectomy for traumatic brain injury. J Neurosurg 128(5):1547-1552, 2018

23. Wang S, Cheng $H$, Dai G, Wang $X$, Hua R, Liu X, Wang $P$, Chen G, Yue W, An Y: Umbilical cord mesenchymal stem cell transplantation significantly improves neurological function in patients with sequelae of traumatic brain injury. Brain Res 1532:76-84, 2013

24. Weiner LP: Definitions and criteria for stem cells. Methods Mol Biol 438:3-8, 2008

25. Werner $\mathrm{C}$, Engelhard K: Pathophysiology of traumatic brain injury. Br J Anaesth 99:4-9, 2007

26. Zemlan F, Rosenberg W, Luebbe P: Quantification of axonal injury in traumatic brain injury: Affinity purification and characterization of cerebrospinal fluid tau proteins. J Neurochem 72(2):741-750, 1999 